\title{
Longitudinal associations of social cognition and substance use in childhood and early adolescence: findings from the Avon Longitudinal Study of Parents and Children
}

\author{
Meg E. Fluharty ${ }^{1,2,4} \oplus$ Jon Heron ${ }^{3} \cdot$ Marcus R. Munafó ${ }^{1,2}$
}

Received: 1 April 2017 / Accepted: 12 October 2017 / Published online: 20 October 2017

(C) The Author(s) 2017. This article is an open access publication

\begin{abstract}
Substance use is associated with impaired social cognition. Experimental studies have shown that acute intoxication of alcohol, tobacco, and cannabis decreases the performance in non-verbal, social communication and theory of mind tasks. However, in epidemiological studies the temporal direction of this association has gone relatively unstudied. We investigated both directions of association within an adolescent birth cohort: the association of social cognition with subsequent substance use, and the association of early substance use with subsequent social cognition. We used data from the Avon Longitudinal Study of Parents and Children, a UK birth cohort. Logistic regression indicated that poor childhood non-verbal communication was associated with decreased odds of adolescent alcohol (OR 0.70, 95\% 0.54-0.91), tobacco (OR 0.62, 95\% CI 0.47-0.83), and cannabis use (OR 0.62, 95\% CI 0.46-0.83). Early adolescent substance use was associated with increased odds of poor social communication (alcohol: OR 1.46, 95\% CI 0.99-2.14; tobacco: OR 1.95, 95\% CI 1.33-2.86) and poor social reciprocity (alcohol: OR 1.57, 95\% CI 1.18-2.09; tobacco: OR
\end{abstract}

Electronic supplementary material The online version of this article (doi:10.1007/s00787-017-1068-x) contains supplementary material, which is available to authorized users.

Meg E. Fluharty

meg.fluharty@bristol.ac.uk

1 MRC Integrative Epidemiology Unit (IEU) at the University of Bristol, Bristol, UK

2 School of Experimental Psychology, UK Centre for Tobacco and Alcohol Studies, University of Bristol, Bristol, UK

3 School of Community and Social Medicine, University of Bristol, Bristol, UK

4 School of Experimental Psychology, University of Bristol, 12a Priory Road, Bristol BS8 1TU, UK
1.92, 95\% CI 1.43-2.58; cannabis: OR 1.54, 95\% CI 1.162.05). Overall, the relationship between social cognition and substance use was different in each temporal direction. Poor non-verbal communication in childhood appeared protective against later substance use, while adolescent substance use was associated with decreased social cognitive performance.

Keywords Social cognition - Substance use · Adolescence $\cdot$ Epidemiology $\cdot$ ALSPAC

\section{Introduction}

Alcohol, tobacco, and cannabis are the most commonly used substances worldwide [1-3]. In 2016, the Global Drugs Survey found that $93 \%$ of respondents reported drinking, $60 \%$ smoking tobacco, and $63 \%$ using cannabis within the past 12 months [4]. Several studies have suggested that acute administration of these substances, and/or prolonged use and abuse of these substances, is associated with deficits in social cognition (i.e., psychological processes involved in social interaction, comprising self-knowledge, perception of others, and motivational understanding). These deficits may include social (i.e., pragmatic) or non-verbal (i.e., emotion processing) communication, and/or Theory of Mind (ToM) (i.e., the ability to attribute complex mental states to others) processes, such as social reciprocity.

Studies indicate that alcohol, tobacco, and cannabis may disrupt non-verbal communication: acute intoxication from alcohol is associated with decreased reactivity to threat cues [5], while alcohol-dependent individuals display reduced accuracy in judging sadness and disgust, and require greater emotional intensity to detect fear and anger [6]. These impairments persist when alcohol-dependent individuals are detoxified [7], and can be sustained up to 2 months into 
sobriety [8]. In daily cigarette smokers, deficits become apparent when individuals are tobacco-deprived. Acute withdrawal in smokers is associated with diminished processing of happy faces relative to neutral faces [9], and disrupted attentional bias to facial stimuli [10]. Additionally, chronic cannabis use is associated with a reduced ability to identify emotions, particularly negative emotions [11]. However, the acute effects of different cannabinoids are distinct, with $\Delta$-9-tetrahydrocannabinol (THC) impairing affect recognition, but cannabidiol (CBD) improving affect recognition [12].

Experimental studies have also shown that acute intoxication with alcohol results in ToM deficits [13]. Alcoholdependent individual display ToM deficits, as they have difficulty identifying their own mental states and that of social partners $[14,15]$. While chronic cannabis users display no change in ToM task performance compared to healthy controls, when compared at the neuroanatomical level they show differential network activation. Heavy cannabis users display less activation in the left parahippocampal gyrus, right precuneus and cuneus, but greater activation in the left cuneus and right anterior cingulate gyrus, suggesting changes at the physiological level [16]. This indicates an aberrant or greater activity of ToM network, and similar changes have been observed in at-risk psychosis populations [16, 17]. Long-term cannabinoid exposure may result in changes and functionality of the endocannabinoid system, and subsequent desensitisation of $\mathrm{CB}_{1}$ receptors may explain the compensatory elevated $\mathrm{CB}_{1}$ receptors elsewhere in the striatum [18] noted in heavy cannabis users compared to controls [19].

However, it remains unclear whether it is substance use itself causing these deficits, or whether these deficits lead to substance use (for example, to enhance certain aspects of social cognition). One argument for the latter is that children that have received social-cognitive interventions within schools and the home have lower rates of substance abuse in adolescence [20, 21]. It is also possible that the relationship between substance use and social cognition may be due to shared risk factors (genetic or environmental).

The relationship between substance use and social cognition is therefore complex, as some deficits occur rapidly with intoxication while others may arise only after longer periods of use. Furthermore, despite evidence of associations of poor social cognition with substance use, there has been relatively little research into the temporal relationships between the two to date. As individuals are most likely to experiment and initiate substance use during their adolescent period [22-24], and several studies have suggested social cognitive problems among hardened users, it is important to further understand whether substance use in early adolescence is associated with later social cognitive deficits, or whether poor social cognition in childhood is associated with later substance use.
This study, conducted using data from the Avon Longitudinal Study of Parents and Children (ALSPC), investigated the temporal associations between poor social cognitive function (non-verbal communication, social communication, and social reciprocity) and substance use behaviours (current, frequent, and age of onset). We examined the association of poor childhood social cognition with subsequent adolescent substance use, and the association of early substance use behaviour with subsequent social cognition. We hypothesised that there would be associations between poor social cognition and substance use in both temporal directions.

\section{Methods}

\section{Participants}

The Avon Longitudinal Study of Parents and Children (ALSPAC) is a prospective, population-based birth cohort study that recruited 14,541 pregnant women resident in Avon, UK, with expected delivery dates from April 1st 1991 to December 31st 1992 (http://www.alspac.bris. ac.uk). Information has been collected on the participants and their offspring from over 60 questionnaires and 9 clinic assessments [25]. The study website contains details of all the data that is available through a fully searchable data dictionary (http://www.bris.ac.uk/alspac/researchers/data-access/data-dictionary/). The study included 13,617 mother-offspring pairs from singleton live births who survived to at least 1 year; only these are considered here. Ethics approval for the study was obtained from the ALSPAC Ethics and Law Committee and the Local Research Ethics Committee.

The analysis of the association between childhood social cognition and subsequent substance use was restricted to the offspring of parents who had completed the Social and Communication Disorders Checklist (SCDC) $(N=3,007)$, SCDC sub-scale $(N=3,058)$ at age 7 , and/or offspring who had completed the Diagnostic Assessment of NonVerbal Accuracy (DANVA) $(N=2,985)$ at age 8 , and offspring who had taken part in the substance use computer task at age $18(N=3,820)$. The analysis of the association between early adolescent substance and subsequent social cognition was further restricted to the offspring who had taken part in the substance use computer task $(N=5,009)$ at age 15 , and offspring whose parents had completed the Social and Communication Disorders Checklist (SCDC) $(N=5,506)$ at age 17. Flow diagrams (Figs. 1 and 2) display the final sample size for each temporal association analysis (see Supplementary Figure 1 for a longitudinal representation of assessments). 


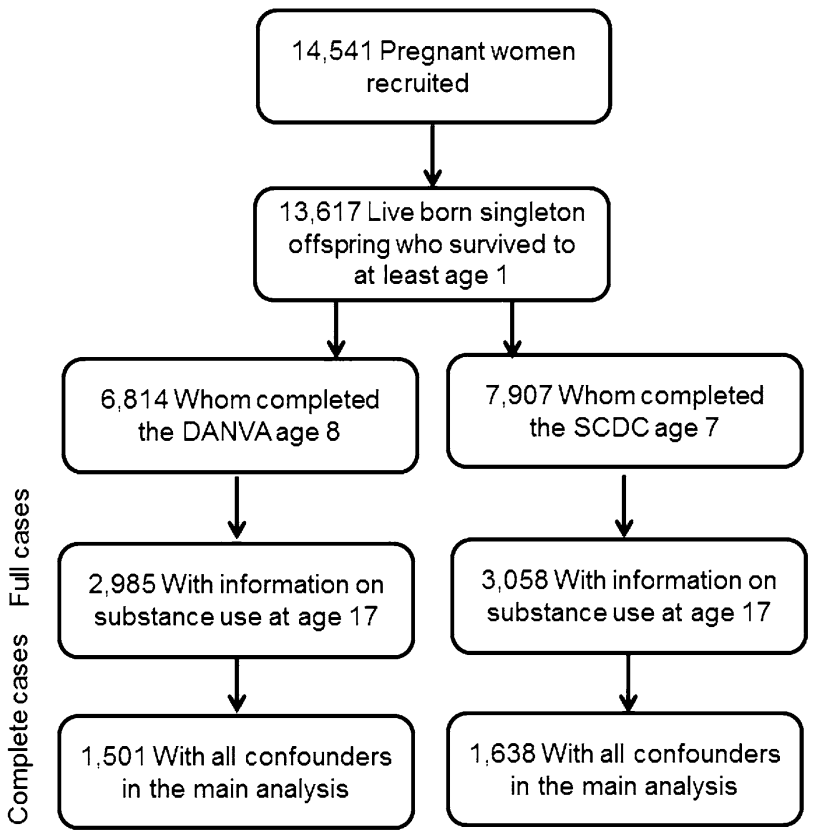

Fig. 1 Flow diagram of final sample size in analysis of childhood social cognition (age 7/8) predicting adolescent substance use (age 18)

\section{Measures}

\section{Social cognition}

Non-verbal communication at age 8 was measured via computer session during a clinic visit using the faces subset of the DANVA [26]. This contains 24 photographs of children's faces displaying an either high or low intensity version of the following emotions: happy, sad, fear, or anger. Each photograph was displayed to the children for $2 \mathrm{~s}$ and they responded as to what emotion they perceived. Scoring $\geq 7$ total errors on the DANVA was coded as poor performance [26]. Social communication was measured by maternal completion of SCDC at offspring age 7 and 17 via questionnaire, scoring $\geq 8$ out of a possible of 24 was coded as poor performance [27]. Social reciprocity at age 7 and 17 was derived from five questions on the SCDC that were specifically designed to measure social reciprocity [28, 29]. Responses of yes to $\geq$ three questions were coded as poor performance.

\section{Substance use}

Current use of alcohol, tobacco, and cannabis at age 15 was collected via computer session during a clinic visit. Individuals were classified as either current or non-users of each substance. Individuals reporting $\geq 20$ drinks in the past 6 months, smoking cigarettes in the past 30 days, or using cannabis in the past 12 months were classified as

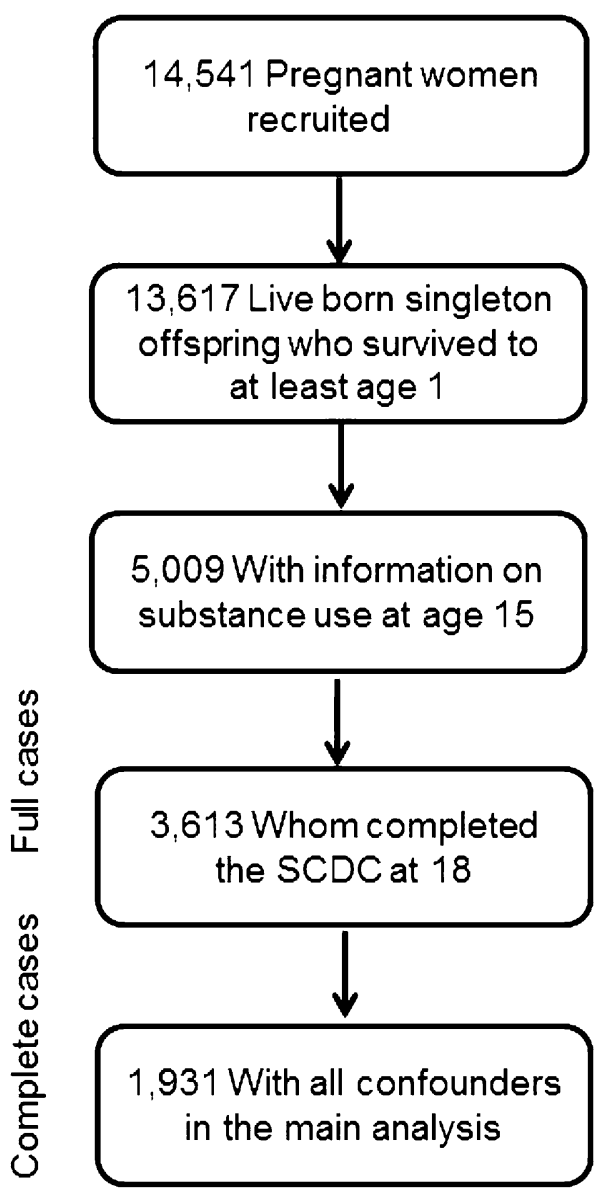

Fig. 2 Flow diagram of final sample size in analysis of adolescent substance (age 15) use predicting social cognition (age 18)

current users of each respective substance. Additionally, age 18 measures of alcohol, tobacco and cannabis use were collected via a computer-based assessment during a clinic visit. Individuals were classified as users of each substance, and a user of all three substances if appropriate. Individuals scoring $\geq 8$ on the Alcohol Use Disorders Identification Test (AUDIT), smoking cigarettes in the past 30 days, or using cannabis in the past 12 months were classified as users of each respective substance. Due to widespread acceptance of alcohol use in the UK, the alcohol use variable was restricted to hazardous use on the AUDIT rather than an ever/never response, as never drinkers may differ in regards to other societal factors comparable to social drinkers (e.g., abstainers for religious reasons [30,31], or individuals with high anxiety [32]). First, individuals using all three substances were additionally classified as multi-substance users, while individuals using one to two substances were classified as non multi-substance users. Second, frequency of use was categorised as either non-weekly or weekly use. Finally, age of onset was a categorical measure based on self-reported first use of each respective substance. 


\section{Confounders}

Based on the literature, risk factors for poor social cognition and substance use were considered as potential confounders. These included: (1) pre-birth/demographic confounders (sex [33, 34], parity [35, 36] and socioeconomic measures [37-42] including maternal social class, maternal education status, maternal home ownership status, and maternal age) as measured by baseline maternal questionnaire; (2) maternal substance use [43, 44] confounders (maternal cannabis use at offspring age 9, maternal binge drinking and smoking at offspring age 12) collected via maternal questionnaire at offspring ages 9 and/ or 12; (3) childhood confounders (IQ [34, 45] measured by the Wechsler Intelligence Scale for Children-III [46], victimisation [47-49] measured by a modified version of the Bullying and Friendship Interview Schedule [50], borderline personality $[51,52]$ measured via interview, and peer problems [53] measured via interview, and The Strengths and Difficulties Questionnaire [54]) all collected via clinic assessment at age 8 or maternal questionnaire. Additionally, for the analysis of early substance use and subsequent social cognition, confounders included (4) previous incidence of poor social cognition (age 7 SCDC and SCDC sub-scale scores, as described above).

\section{Statistical Analysis}

First, we examined the association of social cognition at age $7 / 8$ (exposure) with subsequent substance use behaviour at age 18 (outcome). Next, we examined the association of early substance use behaviours at age 15 (exposure) with subsequent social cognition at age 17 (outcome). We assessed both temporal relationships before and after adjustment for covariates using logistic regression. We examined the impact of confounding by comparing unadjusted results with those adjusted for pre-birth/demographics confounders (model 1), and then additionally and cumulatively maternal substance use (model 2 ), childhood confounders (model 3), and (for the association of early adolescent substance use with subsequent social cognition) history of social cognition at age 7/8 (model 4). Finally, we ran a second set of confounder-adjusted analyses only including the complete cases from model 3 (for the association of childhood social cognition with subsequent substance use) or 4 (for the association of early adolescent substance use with subsequent social cognition). Both analyses were conducted unstratified and stratified by sex. Each analysis was conducted in full (total sample) and complete cases (sample restricted to data available at both time-points). Analyses were conducted in Stata version 13 (Stata Corp LP, College Station TX USA).

\section{Secondary analysis}

Additionally, a secondary analysis was conducted after initial investigation of the DANVA exposure results. This followed the same statistical procedure as above but investigated response accuracy to individual emotions (happy, sad, fear anger) and level of affect intensity (low to high) of emotions as opposed to task accuracy as a whole.

\section{Results}

\section{Characteristics of participants}

Data were available on $N=3058$ participants for the analysis of childhood social cognition with subsequent substance use, and $N=3613$ for the analysis of early adolescent substance use with subsequent social cognition. Characteristics of these participants are shown in Table 1. Confounder characteristics and associations with each outcome are presented in Supplementary Table S1. The results presented below are from the fully adjusted models. Unadjusted and partially adjusted models are presented in Supplementary Tables (S2-S4). In general, sex-stratified analyses did not indicate any clear differences in the strength of association observed for males and females separately. The results are therefore presented unstratified, except where indicated, with sex-stratified analyses presented in Supplementary Tables S5-S8.

\section{Association of childhood social cognition (age 7/8) with adolescent substance use (age 18)}

\section{Non-verbal communication}

Poor non-verbal communication was associated with moderately decreased odds of alcohol (fully adjusted OR 0.70, 95\% CI 0.54-0.91, $P=0.007$ ), tobacco (fully adjusted OR $0.62,95 \%$ CI $0.47-0.83, P=0.001$ ), and cannabis use (fully adjusted OR $0.62,95 \%$ CI $0.46-0.83, P=0.001)$. These results are shown in Table 2. No clear evidence of association was observed for age of onset, or frequency of use (non-weekly/weekly) at age 18 (see Supplementary Tables S2-S3).

\section{Social communication and social reciprocity}

There was no clear evidence of an association of either poor social communication or social reciprocity with alcohol, tobacco, cannabis, or all substance use. These results are shown in Table 2. Additionally, no clear evidence of 
Table 1 Characteristics of participants

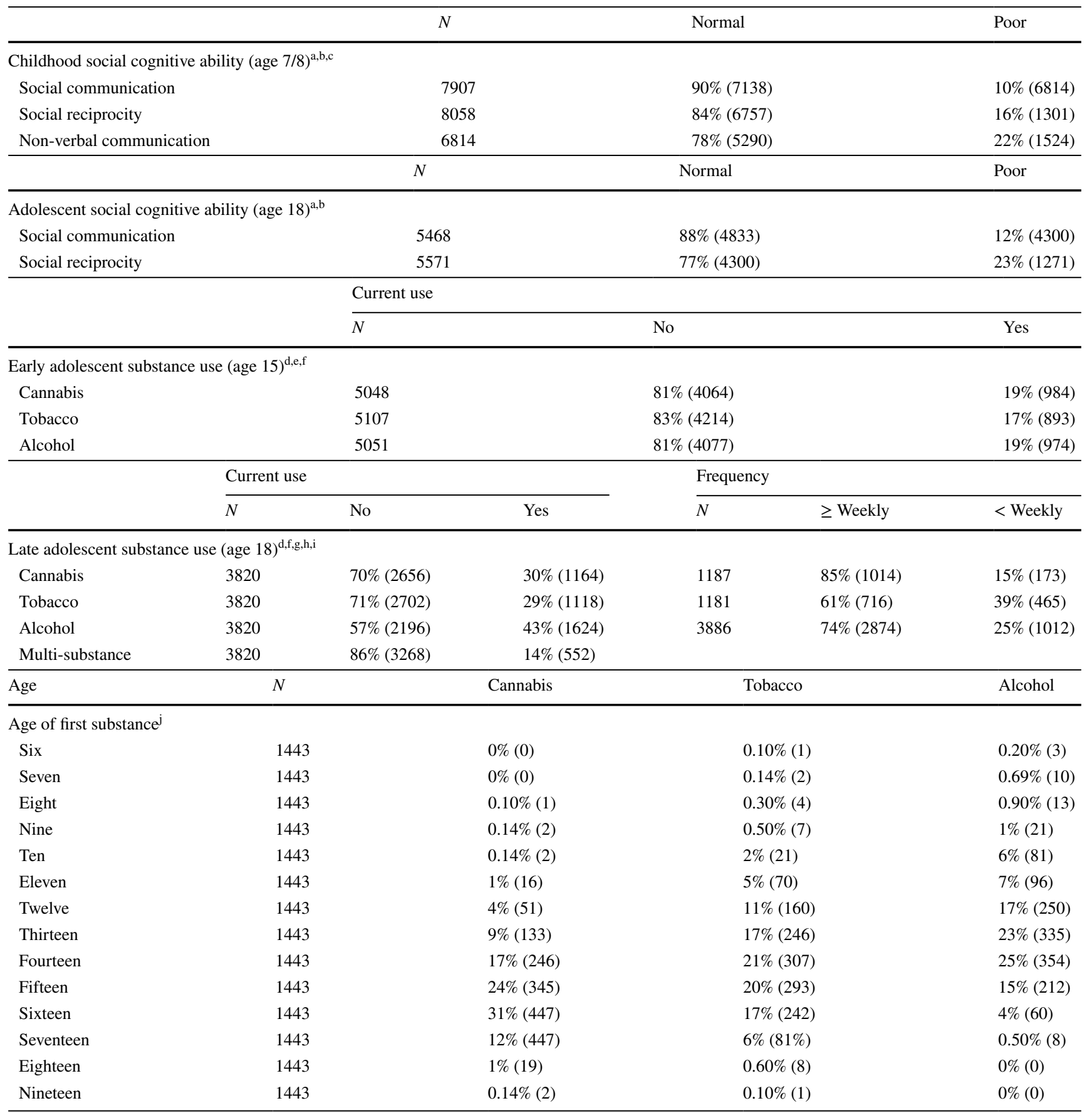

a Poor social communication: total score of $\geq 16$ on the SCDC

${ }^{b}$ Poor social reciprocity: scoring yes on $\geq 3$ from 5 sub questions on social reciprocity on the SCDC

${ }^{c}$ Poor non-verbal communication: $\geq 7$ total errors on the DANVA

${ }^{\mathrm{d}}$ Current tobacco use: use of tobacco is past 30 days

${ }^{\mathrm{e}}$ Current alcohol use: $\geq 20$ drinks in past 6 months

${ }^{\mathrm{f}}$ Current cannabis use: use of cannabis in past 12 months

${ }^{\mathrm{g}}$ Current alcohol use: $\geq 8$ AUDIT

${ }^{\mathrm{h}}$ Multi-substance users were classified as being current users of all three substances

${ }^{\mathrm{i}}$ Frequency of use: measure of less or more than weekly use

${ }^{\mathrm{j}}$ Age of first use: categorical age of first use as measured by computerised interview 
association was observed for age of onset, or frequency of use (non-weekly/weekly) at age 18 (see Supplementary Tables S2-S3).

\section{Secondary analyses}

To further investigate the association of non-verbal communication and current substance use, we investigated the DANVA by individual emotion and intensity. There was no clear pattern of association across the individual emotions (see Supplementary Table S4). However, individuals displaying reduced ability to identify emotions in general, as demonstrated by poor identification of both 'low' and 'high' intensity emotionally expressive faces, had decreased odds of substance use onset, similar to the results seen above. Poor identification of low and high intensity faces was associated with decreased odds of alcohol, tobacco, and cannabis use, and this was robust to adjustment (see Table 3 for details).

\section{Association of early adolescent substance use (age 15) with later social cognition (age 18)}

\section{Social communication}

Increased odds of poor social communication was associated with earlier adolescent alcohol (fully adjusted OR $1.46,95 \%$ CI $0.99-2.14, P=0.051$ ), and tobacco use (fully adjusted OR $1.95,95 \%$ CI $1.33-2.86, P=0.001)$. There was no clear evidence of an association of poor social communication with earlier cannabis use. These results are shown in Table 4. In stratified analyses, associations were slightly stronger for males, with respect to tobacco outcomes.

\section{Social reciprocity}

Increased odds of poor social reciprocity was associated with earlier adolescent alcohol (fully adjusted OR 1.57, 95\% CI 1.18-2.09, $P=0.002$ ), tobacco (fully adjusted OR $1.92,95 \%$ CI $1.43-2.58, P=<0.001$ ), and cannabis use (fully adjusted OR $1.54,95 \%$ CI $1.16-2.05, P=0.003$ ). These results are shown in Table 4. In stratified analyses, associations were slightly stronger for males, with respect to tobacco outcomes (see Supplementary Tables S8).

\section{Discussion}

Our results indicate that, in this cohort, poor non-verbal communication at age 8 is associated with decreased alcohol, tobacco, and cannabis use. Adjustment for prebirth/demographic, maternal, and childhood confounders strengthened the associations for tobacco and cannabis use, but weakened the associations for alcohol. We analysed individual emotions within the DANVA to identify whether sensitivity to specific emotions were driving this association. No pattern of association was found for individual emotions, although poor identification of both low and high intensity of emotional expression was associated with alcohol, tobacco, cannabis, and all substance use. Adjustment for confounders strengthened the associations for alcohol, tobacco, and cannabis, but weakened the association for all substance use. Interestingly, poor non-verbal communication appeared to be protective against later substance use; thus the deficits in non-verbal communication previously reported in substance users are more likely to be the outcome of prolonged use $[6-8,10,11]$, as opposed to reflecting self-medication of these deficits. In the opposite temporal direction, our results indicate that current alcohol, tobacco, and/or cannabis use at age 15 is associated with poor social communication and social reciprocity at 17 . In all cases, adjustment for pre-birth, maternal, childhood, or previous indication of poor social cognition (age 7) did not substantially alter these associations. As both analyses adjust for previous indication of poor social cognition prior to the onset of any substance use (age 7), this suggests that being a current user of alcohol, tobacco, and cannabis may have a substantial impact on social cognitive abilities.

Generally, these analyses suggest that social cognitive deficits may result from the initiation and/or regular use of these substances. While previous literature has suggested these social cognitive deficits can arise during periods of acute intoxication [5, 12] or withdrawal [10], our results suggest these deficits remain present over longer periods of time among users. Alcohol dependence has been associated with impaired semantic memory (i.e., deficits general knowledge accumulated through personal experience). As semantic memory may be necessary for the maintenance of social networks [55], this may subsequently lead to more specific social cognitive deficits [14]. Prolonged nicotine exposure may dysregulate the hypothalamic-pituitary-adrenal system, resulting in the hypersecretions of cortisol and alterations in the activity of the associated monoamine neurotransmitter system, which contributes to stress-regulation [56]. This may result in individuals being more susceptible to environmental stressors and associated difficulties with affect and emotional regulation $[57,58]$. Finally, evidence from imaging studies indicate neuroanatomical changes in heavy cannabis uses associated with prolonged endocannabinoid exposure, 


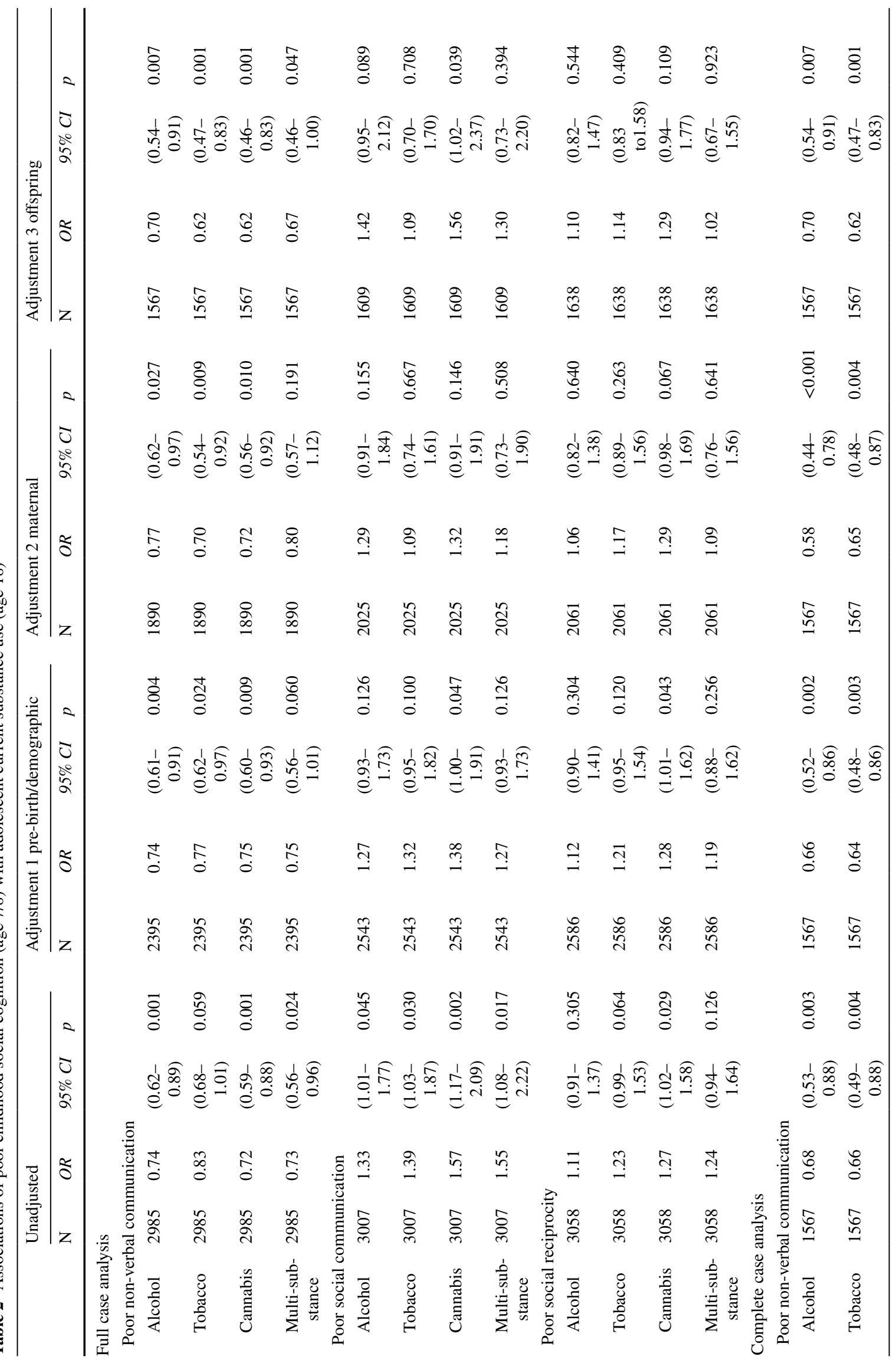




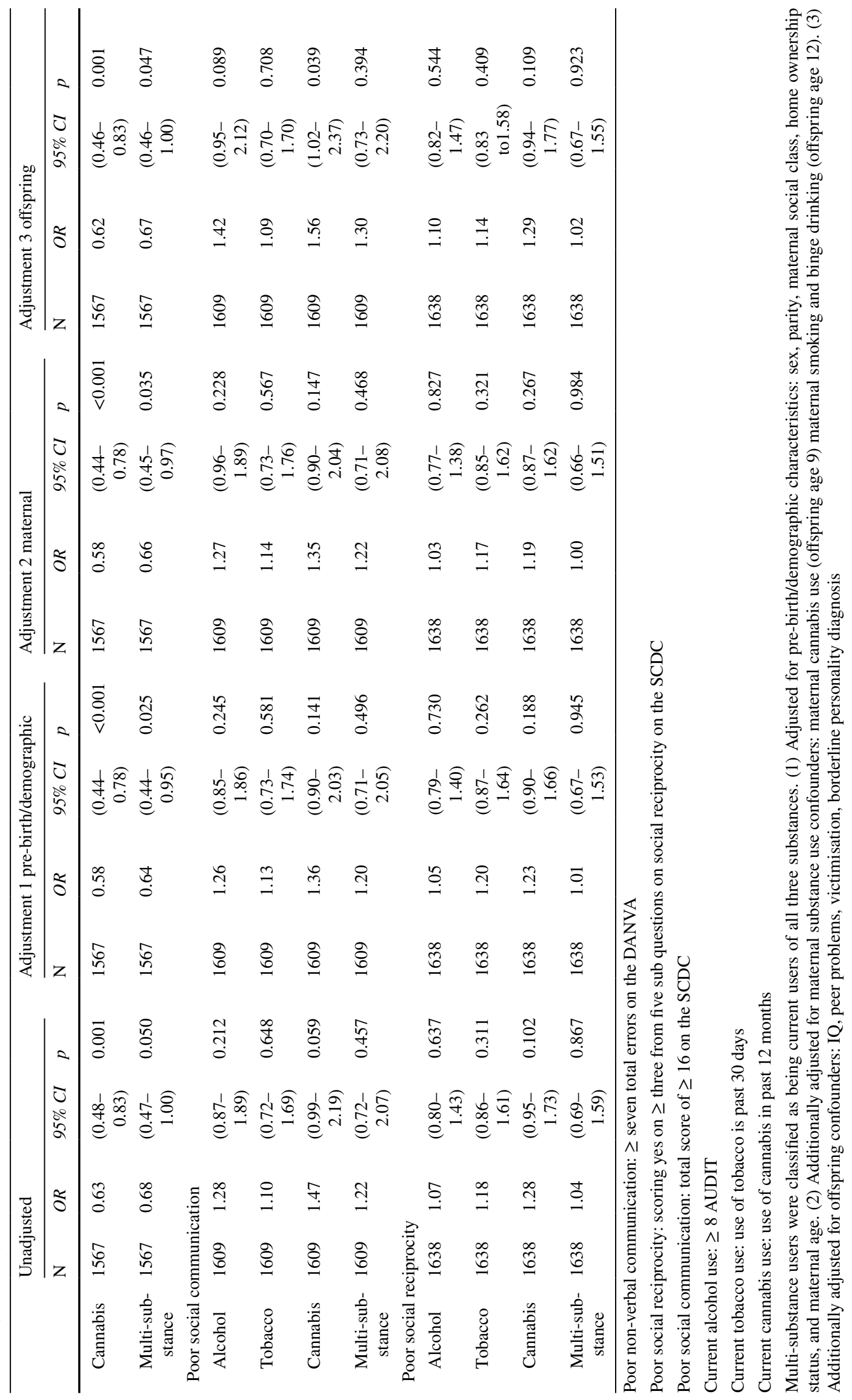




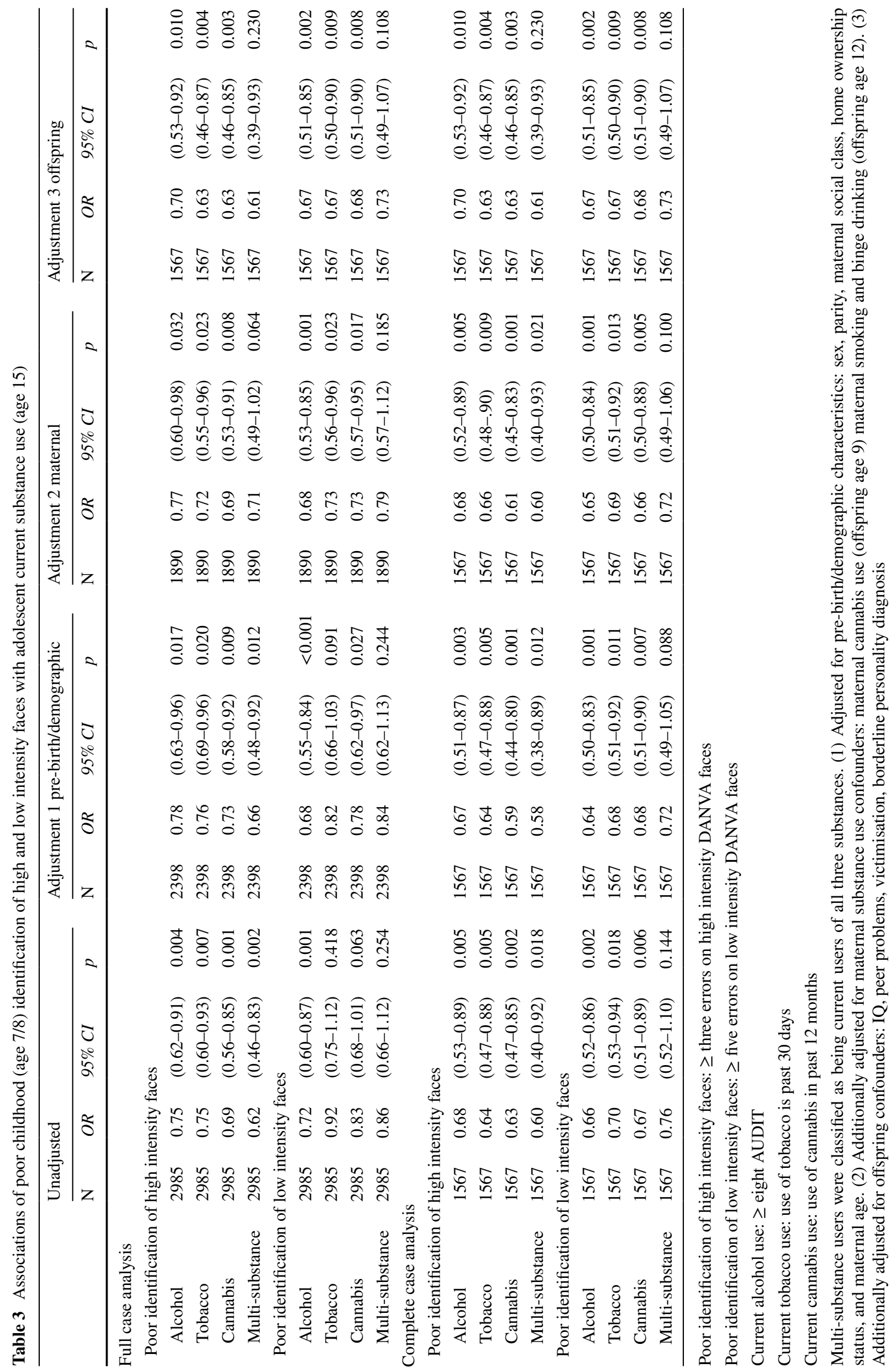




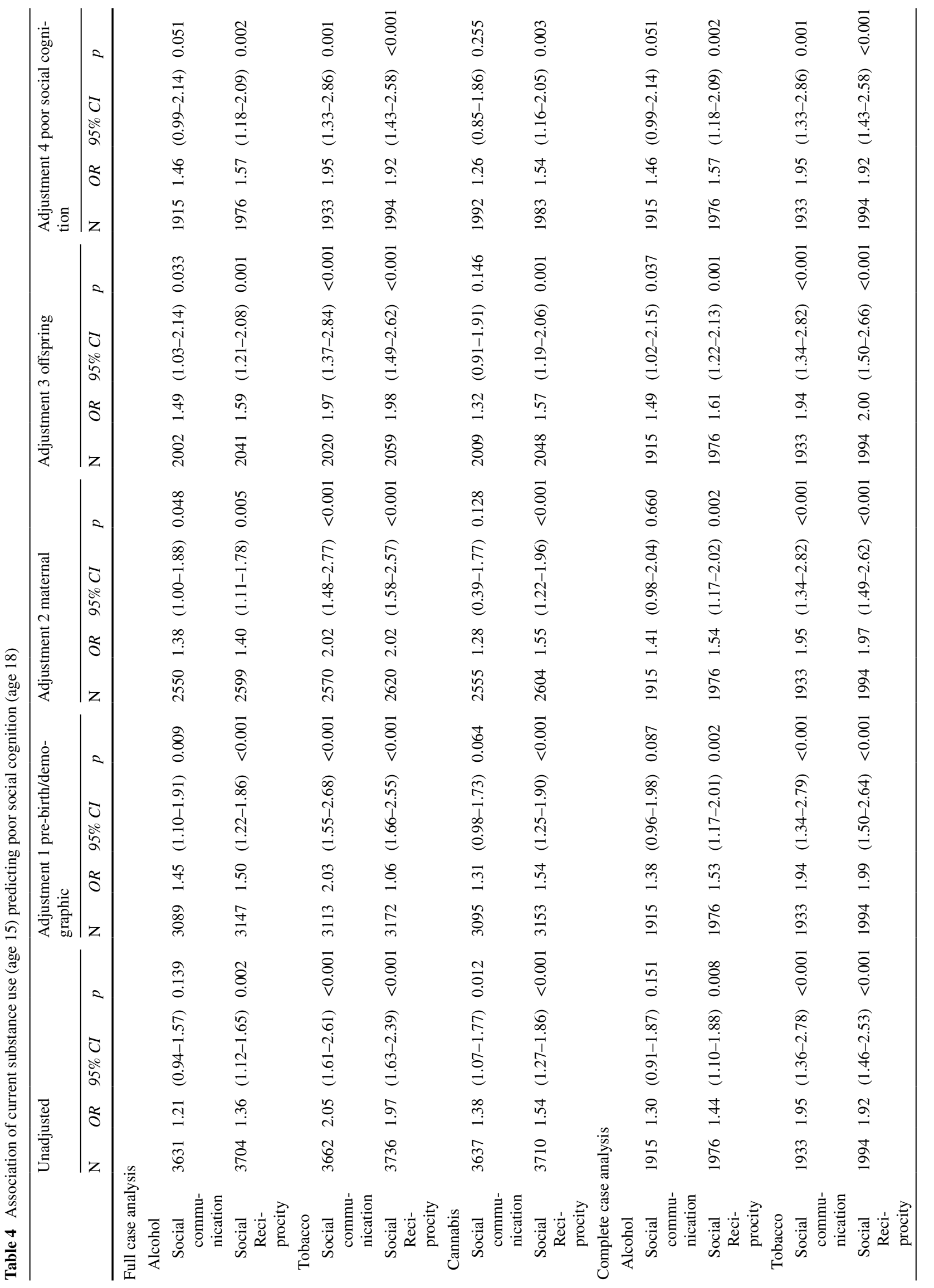


and the subsequent desensitisation of $\mathrm{CB}_{1}$ receptors in the brain, requiring compensatory $\mathrm{CB} 1$ receptor activity elsewhere in the striatum [16-19]. Previous literature indicates strong familial bonds and open communication within families and schools may serve as a protective factor, or help to delay adolescent substance initiation [59-62]. However, in the other temporal direction (i.e., poor social cognition and subsequent substance use), there is currently little evidence. Our analyses help to rule out the possibility of reverse causality, and strengthen our findings that substance use is associated with later impaired social cognition. Additionally, this analysis suggested that poor non-verbal communication may in fact be protective with respect to subsequent substance use. While this is clearly an area that warrants additional research and replication, one possible explanation for this finding is that adolescents with poor emotion recognition skills may less likely to have larger social groups [63, 64] and therefore less likely to engage in substance use due to less social inclusion [65-68].

Strengths of this study include a rich data set with multiple social cognitive and substance use variables collected at several time-points throughout the adolescence and early adulthood. This allows for the analysis of both temporal directions as well as examining different facets of social cognition. Additionally, a robust approach was taken to minimise confounding, using a range of possible confounders from pre-birth throughout adolescence. There are also some limitations in our study to consider. First, some of our exposures were self-reported by the child (DANVA) while others were parent-completed (SCDC and DAWBA). Previous studies have indicated parental rating of offspring well-being to be more positive compared to self-report by offspring [69]. Similarly, the maternal-reported measure of SCDC taken when offspring were aged 17 may be capturing a breakdown in family communication or adolescent disobedience, as opposed to social cognition, due to the generally rebellious nature of the adolescent period. However, a recent genome-wide association study conducted in ALSPAC found evidence of a genome-wide association of SCDC measures at age 17, suggesting there is a genetic architecture of social communication that can be reliably captured by the maternal SCDC measure [70]. Second, SCDC scores are known to remain constant across age groups [27], while studies have indicated DANVA scores to improve with age [26]. This is a potential problem if the ranking of scores across the population is not consistent; however, previous ALSPAC studies have indicated a test-retest reliability in the DANVA of 0.84 [71]. Third, as maternal data are collected frequently and are more extensive than partner data within ALSPAC, we only investigated the impact of maternal confounding. Fourth, our substance use outcomes are all reliant on self-report and we were not able to biochemically validate these 
responses. Additionally, we drew our outcomes from age 18 , which provided us with a large sample size of individuals whom had ever used substances. However, there were notably fewer individuals answering questions regarding frequency of use, which may have contributed to the low power for these analyses. Fifth, it is possible that our variable for multi-substance current use simply reflects current cannabis use, since cannabis users typically also consume alcohol and tobacco [72]. Finally, there was evidence of differential loss to follow-up, as some children with high SCDC scores, were slightly more likely to drop out of the study before substance use and social cognition outcome data was obtained. However, this does not necessarily imply selection bias in the association between social cognition and later substance use [73], and comparisons of full and complete cases display little change in results due to sample size.

Overall, we found differing patterns of relationships between social cognition and substance use behaviour dependent on the specific social cognition examined and temporal direction of association. While poor non-verbal communication in childhood appeared to have protective factors against later substance use, early adolescent substance use was associated with decreased social cognitive performance. This association would be worth pursuing for replication in cohorts with similar or richer data on social cognitive variables. Furthermore, the use of differing statistical analyses and methods will additionally help to strengthen these findings. Given that causality cannot be inferred from observational data alone, future epidemiological studies investigating these associations should consider alternative statistical techniques. For example, studies can use genetic variants associated with substance use or social communication as proxies for these exposures within a Mendelian randomization framework.

Acknowledgements We are extremely grateful to all the families who took part in this study, the midwives for their help in recruiting the participants, and the whole ALSPAC team, which includes interviewers, computer and laboratory technicians, clerical workers, research scientists, volunteers, managers, receptionists and nurses. The UK Medical Research Council and the Wellcome Trust (Grant Ref: 102215/2/13/2) and the University of Bristol provide core support for ALSPAC. This publication is the work of the authors and MF, JH, and $\mathrm{MM}$ will serve as guarantors for the contents of this paper. The research was specifically funded by a University of Bristol postgraduate research scholarship awarded to MF, and by the Medical Research Council and the University of Bristol (MC_UU_12013/6).

MF and MM are members of the UK Centre for Tobacco and Alcohol Studies, a UKCRC Public Health Research: Centre of Excellence. Funding from the British Heart Foundation, Cancer Research UK, Economic and Social Research Council, Medical, Research Council and the National Institute for Health Research, under the auspices of the UK Clinical Research Collaboration, is gratefully acknowledged.

Author Contributions All authors designed the study. MEF conducted the analysis and drafted the manuscript with input from MRM and JH. All Authors approved the final version of the manuscript for submission.

\section{Compliance with ethical standards}

Role of funding source Nothing declared

Conflict of interest On behalf of all authors, the corresponding author states that there is no conflict of interest.

Open Access This article is distributed under the terms of the Creative Commons Attribution 4.0 International License (http://creativecommons.org/licenses/by/4.0/), which permits unrestricted use, distribution, and reproduction in any medium, provided you give appropriate credit to the original author(s) and the source, provide a link to the Creative Commons license, and indicate if changes were made.

\section{References}

1. Organization WH (2016) WHO global report on trends in tobacco smoking 2000-2025. World Health Organization. http://www. who.int/tobacco/publications/surveillance/reportontrendstobaccosmoking/en/index3.html. Accessed 03 Feb 2017

2. Organization WH Cannabis. http://www.who.int/substance_abuse/ facts/cannabis/en/. Accessed 03 Feb 2017

3. Organization WH Global Information System on Alcohol and Health (GISAH). http://www.who.int/gho/alcohol/en/. Accessed 03 Feb 2017

4. Winstock ARB, M.; Ferris, J.; Maier, L. (2016) What we learned from GDS2016. https://www.globaldrugsurvey.com/wp-content/ uploads/2016/06/TASTER-KEY-FINDINGS-FROM-GDS2016. pdf. Accessed 03 Feb 2017

5. Curtin JJ, Patrick CJ, Lang AR, Cacioppo JT, Birbaume N (2001) Alcohol affects emotion through cognition. Psychol Sci 12(6):527-531. doi:10.1111/1467-9280.00397

6. Donadon MF, Osorio Fde L (2014) Recognition of facial expressions by alcoholic patients: a systematic literature review. Neuropsychiatr Dis Treat 10:1655-1663. doi:10.2147/NDT.S65376

7. Townshend JM, Duka T (2003) Mixed emotions: alcoholics' impairments in the recognition of specific emotional facial expressions. Neuropsychologia 41(7):773-782

8. Kornreich C, Blairy S, Philippot P, Hess U, Noel X, Streel E, Le Bon O, Dan B, Pelc I, Verbanck P (2001) Deficits in recognition of emotional facial expression are still present in alcoholics after mid- to long-term abstinence. J Stud Alcohol 62(4):533-542

9. Leventhal AM, Munafo M, Tidey JW, Sussman S, Monterosso JR, Sun P, Kahler CW (2012) Anhedonia predicts altered processing of happy faces in abstinent cigarette smokers. Psychopharmacology 222(2):343-351. doi:10.1007/s00213-012-2649-5

10. Adams S, Attwood AS, Munafo MR (2014) Effects of nicotine and nicotine expectancy on attentional bias for emotional stimuli. Nicotine Tobacco Research. doi:10.1093/ntr/ntu219

11. Bayrakci A, Sert E, Zorlu N, Erol A, Saricicek A, Mete L (2015) Facial emotion recognition deficits in abstinent cannabis dependent patients. Compr Psychiatry 58:160-164. doi:10.1016/j. comppsych.2014.11.008

12. Hindocha C, Freeman TP, Schafer G, Gardener C, Das RK, Morgan CJ, Curran HV (2015) Acute effects of delta-9-tetrahydrocannabinol, cannabidiol and their combination on facial emotion recognition: a randomised, double-blind, placebo-controlled study 
in cannabis users. Eur Neuropsychopharmacol 25(3):325-334. doi:10.1016/j.euroneuro.2014.11.014

13. Mitchell IJ, Beck SR, Boyal A, Edwards VR (2011) Theory of mind deficits following acute alcohol intoxication. Eur Addict Res 17(3):164-168. doi:10.1159/000324871

14. Nandrino JL, Gandolphe MC, Alexandre C, Kmiecik E, Yguel J, Urso L (2014) Cognitive and affective theory of mind abilities in alcohol-dependent patients: the role of autobiographical memory. Drug Alcohol Depend 143:65-73. doi:10.1016/j. drugalcdep.2014.07.010

15. Bosco FM, Capozzi F, Colle L, Marostica P, Tirassa M (2014) Theory of mind deficit in subjects with alcohol use disorder: an analysis of mindreading processes. Alcohol Alcohol 49(3):299307. doi:10.1093/alcalc/agt148

16. Roser P, Lissek S, Tegenthoff M, Nicolas V, Juckel G, Brune M (2012) Alterations of theory of mind network activation in chronic cannabis users. Schizophr Res 139(1-3):19-26. doi:10.1016/j. schres.2012.05.020

17. Marjoram D, Job DE, Whalley HC, Gountouna VE, McIntosh AM, Simonotto E, Cunningham-Owens D, Johnstone EC, Lawrie S (2006) A visual joke fMRI investigation into Theory of Mind and enhanced risk of schizophrenia. Neuroimage 31(4):1850 1858. doi:10.1016/j.neuroimage.2006.02.011

18. Romero J, Garcia-Palomero E, Castro JG, Garcia-Gil L, Ramos JA, Fernandez-Ruiz JJ (1997) Effects of chronic exposure to delta9-tetrahydrocannabinol on cannabinoid receptor binding and mRNA levels in several rat brain regions. Brain Res Mol Brain Res 46(1-2): 100-108

19. Sim-Selley LJ (2003) Regulation of cannabinoid CB1 receptors in the central nervous system by chronic cannabinoids. Crit Rev Neurobiol 15(2):91-119

20. Hawkins JD, Catalano RF, Kosterman R, Abbott R, Hill KG (1999) Preventing adolescent health-risk behaviors by strengthening protection during childhood. Arch Pediat Adol Med 153(3):226-234

21. Battistich V, Schaps E, Watson M, Solomon D (1996) Prevention effects of the child development project: early findings from an ongoing multisite demonstration trial. J Adolescent Res 11(1):1235. doi: $10.1177 / 0743554896111003$

22. Rhee SH, Hewitt JK, Young SE, Corley RP, Crowley TJ, Stallings MC (2003) Genetic and environmental influences on substance initiation, use, and problem use in adolescents. Arch Gen Psychiatry 60(12):1256-1264. doi:10.1001/archpsyc.60.12.1256

23. King KM, Chassin L (2007) A prospective study of the effects of age of initiation of alcohol and drug use on young adult substance dependence. J Stud Alcohol Drugs 68(2):256-265

24. Agrawal A, Grant JD, Waldron M, Duncan AE, Scherrer JF, Lynskey MT, Madden PA, Bucholz KK, Heath AC (2006) Risk for initiation of substance use as a function of age of onset of cigarette, alcohol and cannabis use: findings in a Midwestern female twin cohort. Prev Med 43(2):125-128. doi:10.1016/j. ypmed.2006.03.022

25. Boyd A, Golding J, Macleod J, Lawlor DA, Fraser A, Henderson J, Molloy L, Ness A, Ring S, Smith GD (2013) Cohort profile: the 'Children of the 90 s'-the index offspring of the Avon Longitudinal Study of Parents and Children. Int J Epidemiol 42(1):111-127. doi:10.1093/ije/dys064

26. Nowicki S, Duke MP (1994) Individual-differences in the nonverbal-communication of affect - the diagnostic-analysis of nonverbal accuracy scale. J Nonverbal Behav 18(1):9-35. doi:10.1007/ Bf02169077

27. Robinson EB, Munir K, Munafo MR, Hughes M, McCormick MC, Koenen KC (2011) Stability of autistic traits in the general population: further evidence for a continuum of impairment. $\mathbf{J}$ Am Acad Child Adolesc Psychiatry 50(4):376-384. doi:10.1016/j. jaac.2011.01.005
28. Skuse D, Warrington R, Bishop D, Chowdhury U, Lau J, Mandy W, Place M (2004) The developmental, dimensional and diagnostic interview (3di): a novel computerized assessment for autism spectrum disorders. J Am Acad Child Adolesc Psychiatry 43(5):548-558. doi:10.1097/00004583-200405000-00008

29. Skuse DH, Mandy WPL, Scourfield J (2005) Measuring autistic traits: heritability, reliability and validity of the social and communication disorders checklist. Brit J Psychiat 187:568-572. doi:10.1192/bjp.187.6.568

30. Wallace JM Jr, Brown TN, Bachman JG, LaVeist TA (2003) The influence of race and religion on abstinence from alcohol, cigarettes and marijuana among adolescents. J Stud Alcohol 64(6):843-848

31. Michalak L, Trocki K, Bond J (2007) Religion and alcohol in the U.S. National Alcohol Survey: how important is religion for abstention and drinking? Drug Alcohol Depend 87(2-3):268280. doi:10.1016/j.drugalcdep.2006.07.013

32. Pardini D, White HR, Stouthamer-Loeber M (2007) Early adolescent psychopathology as a predictor of alcohol use disorders by young adulthood. Drug Alcohol Depend 88(Suppl 1):S38S49. doi:10.1016/j.drugalcdep.2006.12.014

33. Evans EA, Grella CE, Washington DL, Upchurch DM (2017) Gender and race/ethnic differences in the persistence of alcohol, drug, and poly-substance use disorders. Drug Alcohol Depend 174:128-136. doi:10.1016/j.drugalcdep.2017.01.021

34. Skuse DH, Mandy W, Steer C, Miller LL, Goodman R, Lawrence K, Emond A, Golding J (2009) Social communication competence and functional adaptation in a general population of children: preliminary evidence for sex-by-verbal IQ differential risk. J Am Acad Child Adolesc Psychiatry 48(2):128-137. doi:10.1097/CHI.0b013e31819176b8

35. Argys LM, Rees DI, Averett SL, Witoonchart B (2006) Birth order and risky adolescent behavior. Econ Inq 44(2):215-233. doi:10.1093/ei/cbj011

36. Warren J (1966) Birth order and social behaviour. Psychol Bull 65(1):38-49

37. Buu A, DiPiazza C, Wang J, Puttler LI, Fitzgerald HE, Zucker RA (2009) Parent, family, and neighborhood effects on the development of child substance use and other psychopathology from preschool to the start of adulthood. J Stud Alcohol Drugs 70(4):489-498

38. Stone AL, Becker LG, Huber AM, Catalano RF (2012) Review of risk and protective factors of substance use and problem use in emerging adulthood. Addict Behav 37(7):747-775. doi:10.1016/j.addbeh.2012.02.014

39. Bradley RH, Corwyn RF (2002) Socioeconomic status and child development. Annu Rev Psychol 53:371-399. doi:10.1146/ annurev.psych.53.100901.135233

40. Coyne CA, Langstrom N, Rickert ME, Lichtenstein P, D'Onofrio BM (2013) Maternal age at first birth and offspring criminality: using the children of twins design to test causal hypotheses. Dev Psychopathol 25(1):17-35. doi:10.1017/ S0954579412000879

41. Benjet C (2010) Childhood adversities of populations living in low-income countries: prevalence, characteristics, and mental health consequences. Curr Opin Psychiatry 23(4):356-362. doi:10.1097/YCO.0b013e32833ad79b

42. Lopez-Castroman J (2014) Young maternal age and old paternal age induce similar risk of mental disorders in offspring. Evid Based Ment Health 17(4):100. doi:10.1136/eb-2014-101861

43. Arria AM, Mericle AA, Meyers K, Winters KC (2012) Parental substance use impairment, parenting and substance use disorder risk. J Subst Abuse Treat 43(1):114-122. doi:10.1016/j. jsat.2011.10.001

44. Chassin L, Pitts SC, Prost J (2002) Binge drinking trajectories from adolescence to emerging adulthood in a high-risk sample: 
predictors and substance abuse outcomes. J Consult Clin Psychol 70(1):67-78

45. Trinidad DR, Johnson CA (2002) The association between emotional intelligence and early adolescent tobacco and alcohol use. Pers Indiv Differ 32(1):95-105. doi:10.1016/ S0191-8869(01)00008-3

46. Lavin C (1996) The Wechsler intelligence scale for children third edition and the Stanford-Binet Intelligence scale: fourth edition: a preliminary study of validity. Psychol Rep 78(2):491-496

47. Tharp-Taylor S, Haviland A, D'Amico EJ (2009) Victimization from mental and physical bullying and substance use in early adolescence. Addict Behav 34(6-7):561-567. doi:10.1016/j. addbeh.2009.03.012

48. Dodge KA, Lansford JE, Burks VS, Bates JE, Pettit GS, Fontaine R, Price JM (2003) Peer rejection and social information-processing factors in the development of aggressive behavior problems in children. Child Dev 74(2):374-393

49. Salmivalli C, Lagerspetz K, Bjorkqvist K, Osterman K, Kaukiainen A (1996) Bullying as a group process: participant roles and their relations to social status within the group. Aggress Behav 22(1):1-15. doi:10.1002/ (Sici)1098-2337(1996)22:1<1:Aid-Ab1 > 3.0.Co;2-T

50. Wolke D, Woods S, Stanford K, Schulz H (2001) Bullying and victimization of primary school children in England and Germany: prevalence and school factors. Br J Psychol 92(Pt 4):673-696

51. Trull TJ, Sher KJ, Minks-Brown C, Durbin J, Burr R (2000) Borderline personality disorder and substance use disorders: a review and integration. Clin Psychol Rev 20(2):235-253

52. Roepke S, Vater A, Preissler S, Heekeren HR, Dziobek I (2013) Social cognition in borderline personality disorder. Front Neurosci-Switz 6. doi:ARTN 195 10.3389/fnins.2012.00195

53. Murphy SM, Faulkner DM, Farley LR (2014) The behaviour of young children with social communication disorders during dyadic interaction with peers. J Abnorm Child Psychol 42(2):277289. doi:10.1007/s10802-013-9772-6

54. Goodman R (2001) Psychometric properties of the strengths and difficulties questionnaire. J Am Acad Child Adolesc Psychiatry 40(11):1337-1345. doi:10.1097/00004583-200111000-00015

55. Labouvie-Vief G, Blanchard-Fields F (1982) Cognitive ageing and psychological growth. Ageing Soc 2(2):183-209. doi:10.1017/ S0144686X00009429Published

56. Markou A, Kosten TR, Koob GF (1998) Neurobiological similarities in depression and drug dependence: a self-medication hypothesis. Neuropsychopharmacol 18(3):135-174. doi:10.1016/ S0893-133x(97)00113-9

57. Joormann J, Quinn ME (2014) Cognitive processes and emotion regulation in depression. Depress Anxiety 31(4):308-315. doi:10.1002/da.22264

58. Joormann J, Stanton CH (2016) Examining emotion regulation in depression: a review and future directions. Behav Res Ther 86:35-49. doi:10.1016/j.brat.2016.07.007

59. McArdle P, Wiegersma A, Gilvarry E, Kolte B, McCarthy S, Fitzgerald M, Brinkley A, Blom M, Stoeckel I, Pierolini A, Michels I, Johnson R, Quensel S (2002) European adolescent substance use: the roles of family structure, function and gender. Addiction 97(3):329-336

60. Kliewer W, Murrelle L (2007) Risk and protective factors for adolescent substance use: findings from a study in selected Central American countries. J Adolesc Health 40(5):448-455. doi:10.1016/j.jadohealth.2006.11.148

61. Farrell AD, White KS (1998) Peer influences and drug use among urban adolescents: family structure and parent-adolescent relationship as protective factors. J Consult Clin Psychol 66(2):248-258

62. Spoth R, Redmond C, Shin C, Azevedo K (2004) Brief family intervention effects on adolescent substance initiation: schoollevel growth curve analyses 6 years following baseline. J Consult Clin Psychol 72(3):535-542. doi:10.1037/0022-006X.72.3.535

63. Leppanen JM, Hietanen JK (2001) Emotion recognition and social adjustment in school-aged girls and boys. Scand J Psychol 42(5):429-435

64. Barth JM, Bastiani A (1997) A longitudinal study of emotion recognition and preschool children's social behavior. Merrill Palmer Q 43(1):107-128

65. Urberg KA, Degirmencioglu SM, Pilgrim C (1997) Close friend and group influence on adolescent cigarette smoking and alcohol use. Dev Psychol 33(5):834-844

66. McCrady BS (2004) To have but one true friend: implications for practice of research on alcohol use disorders and social network. Psychol Addict Behav 18(2):113-121. doi:10.1037/0893-164X.18.2.113

67. Shadur J, Hussong A (2014) Friendship intimacy, close friend drug use, and self-medication in adolescence. J Soc Pers Relat 31(8):997-1018. doi:10.1177/0265407513516889

68. Alfaro DLP, Ehlinger V, Spilka S, Ross J, Sentenac M, Godeau E (2017) Alcohol, tobacco and cannabis use: do students with mildintellectual disability mimic students in the general population? Res Dev Disabil 63:118-131. doi:10.1016/j.ridd.2016.10.009

69. Waters E, Stewart-Brown S, Fitzpatrick R (2003) Agreement between adolescent self-report and parent reports of health and well-being: results of an epidemiological study. Child Care Health Dev 29(6):501-509

70. St Pourcain B, Skuse DH, Mandy WP, Wang K, Hakonarson H, Timpson NJ, Evans DM, Kemp JP, Ring SM, McArdle WL, Golding J, Smith GD (2014) Variability in the common genetic architecture of social-communication spectrum phenotypes during childhood and adolescence. Mol Autism 5(1):18. doi:10.1186/2040-2392-5-18

71. Barona M, Kothari R, Skuse D, Micali N (2015) Social communication and emotion difficulties and second to fourth digit ratio in a large community-based sample. Mol Autism 6:68. doi:10.1186/ s13229-015-0063-7

72. Raphael B, Wooding S, Stevens G, Connor J (2005) Comorbidity: cannabis and complexity. J Psychiatr Pract 11(3):161-176

73. Carter KN, Imlach-Gunasekara F, McKenzie SK, Blakely $\mathrm{T}$ (2012) Differential loss of participants does not necessarily cause selection bias. Aust Nz J Publ Heal 36(3):218-222. doi:10.1111/j.1753-6405.2012.00867.x 